\title{
Procesos de remoción en masa inducidos por el terremoto del 27F de 2010 en la franja costera de la Región del Biobío, Chile ${ }^{1}$
}

\author{
María Mardones Flores² y Jorge Rojas Hernández ${ }^{3}$
}

\begin{abstract}
RESUMEN
Se estudian procesos de remoción en masa (PRM) detonados por el megaterremoto 8.8Mw del 27F 2010, en el litoral de Concepción, Región del Biobío, Chile. Se analiza la morfometría y se explican los factores de peligrosidad de 22 eventos. Los tipos de PRM identificados fueron: desprendimiento de roca y suelo, deslizamiento de roca, deslizamiento de suelo, extensión lateral de suelos y remoción en masa mixto. Se revela el fuerte peso de los factores locales como condicionantes de los PRM: pendientes topográficas, manejo de taludes, grado de saturación del suelo, características litológicas y tectónicas. Se concluye que la densidad de los PRM se incrementa hacia el epicentro, pero el número y tamaño de estos no es comparable con la magnitud del sismo; este aspecto estaría relacionado con las características del relieve y con la baja humedad del suelo, dado que el sismo ocurrió en verano (estación seca del clima mediterráneo).
\end{abstract}

Palabras clave: Estabilidad de laderas, caída de rocas, deslizamiento, deslizamiento cosísmico, proceso de remoción en masa

\begin{abstract}
Mass removal process (MRP) are studied, triggered by the $8.8 \mathrm{Mw}$ mega-earthquake

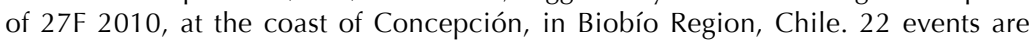
morphometrically evaluated on the field and theirs hazard factors are explained. The types of MRP identified were: rock and soil detachment, rockslide, landslide, lateral spreading and mix mass removal processes. Local factors as determinants of the MRP seem to be strongly influenced by topographic slopes, slope management, soil moisture, lithological and tectonic. It is concluded that the density of MRP increases with the proximity to the epicenter, but the number and size of MRP are not comparable with the magnitude of the earthquake; this aspect would be related to the relief features and the low soil moisture, since the earthquake occurred in summer (dry season of the Mediterranean climate).
\end{abstract}

Key words: slope stability, rock falls, landslides, earthquake-induced landslides, mass removal process

\footnotetext{
1 Este trabajo fue desarrollado en el marco del proyecto Anillo SOC 28. Los autores agradecen por la recopilación de datos y aporte de fotos a los estudiantes de Geología de la Universidad de Concepción: Carolina Cisterna, Karen Díaz, Loreto Donoso, Alonso Figueroa, Olivia Mejías, Carolina Mora, Alex Obregón, Álvaro Ortega, Álvaro Osorio, Ricardo Velásquez; y al Dr. Héctor Carrasco M. e Ing. Héctor Carrasco G. Igualmente, agradecen al Ing. Ernesto Smith y al Técnico Informático Alex Henríquez, por
}

\footnotetext{
la elaboración de las figuras, y a Callum Banfield todos del Centro EULA de la Universidad de Concepción. Artículo recibido el 30 de agosto de 2012, aceptado el 23 de septiembre de 2012 y corregido el 2 de octubre de 2012.

2 Centro EULA, Universidad de Concepción (Chile). E-mail:mmardone@udec.cl

3 Departamento de Sociología y Antropología, Universidad de Concepción (Chile). E-mail: jrojas@udec.cl
} 
A nivel planetario, los grandes terremotos han detonado una variedad de procesos de remoción en masa (PRM) y de erosión que han afectado la estabilidad de taludes, los que han sido documentados en numerosos estudios (Keefer, 1984; Denier et al., 1991; Rauch, 1997; Vargas, 2002; Keefer, 2002; Meunier et al., 2007, Laffaille et al., 2010, Ouimet, 2011, Parker et al., 2011, Schulz et al., 2012). Estos han causado cientos de miles de muertos, billones de dólares de pérdidas económicas y han denudado miles de $\mathrm{km}^{2}$ de suelo (Keefer, 1984). La mayoría de los procesos se han producido a lo largo de fallas y en laderas de montañas escarpadas, con grandes desniveles topográficos (Denier et al., 1991, Laffaille et al., 2010).

Las remociones en masa son fenómenos gravitacionales de movilización lenta o rápida de un determinado volumen de suelo, roca o ambos, en diversas proporciones, con velocidades variables, a lo largo de un talud. Son las manifestaciones morfodinámicas más frecuentes de la inestabilidad de laderas. Los factores internos, que contribuyen a generar estos fenómenos, son: las características litológicas (variaciones de meteorización y permeabilidad de la roca) y morfológicas del relieve (erosión basal, depósitos de sobrecarga de laderas, presencia de cizallas), la estructura y propiedades físicas del suelo, factores tenso-deformativos, la densidad de la cobertura vegetal (deforestación, incendios forestales), etc. Los factores detonantes más frecuentes son: las variaciones en el contenido de agua del suelo (intensidad de lluvia diaria), solicitaciones sísmicas (terremotos), aplicación de cargas estáticas o dinámicas y modificación geométrica de las pendientes (Varnes, 1978; Cruden, 1991; Hauser, 2000).

En el litoral de Concepción (Chile) son recurrentes Ios PRM. Alarcón (1995) contabiliza 88 eventos para el periodo 1960-90 a través de la información registrada en el Diario EI Sur; registro tres veces superior al intervalo 1885-1920 (Essman, 1997). Se reconoce como detonante principal la intensidad de lluvia diaria y entre los factores que han facilitado su desarrollo se mencionan: taludes deforestados, taludes intervenidos para construcción de casas o carreteras (sin estabilizar), pendientes topográficas $>20^{\circ}$, taludes enmantados por gruesas capas de regolita conteniendo arcillas del tipo montmorillonita, etc. Básicamente, el poblamiento de los cerros que rodean el área metropolitana de Concepción, ha incrementado la actividad morfogenética de las laderas durante los inviernos pluviosos (Mardones et al., 2006).

Los PRM cosísmicos son aquellos detonados por sismos de gran magnitud, debido al aumento del esfuerzo cortante, a la disminución de resistencia por el aumento de la presión de poros y a la deformación del suelo asociado a la onda sísmica. Las laderas caen, fallan, debido a que la aceleración gravitacional y sísmica provoca cortas tensiones que superan la fuerza combinada de cohesión y fricción, entre la roca subyacente y los suelos (Meunier et al., 2007).

En 1960, uno de los más grandes terremotos del mundo (M: 9.5) azotó las costas del centro-sur de Chile (USGS), causando numerosos deslizamientos profundos y cientos de deslizamientos superficiales (Davis \& Karzulovic, 1963; Weischet, 1963). PRM fueron observados en los flancos montañosos sobre una franja de entre 8 a $20 \mathrm{~km}$ de ancho, situada aproximadamente $25 \mathrm{~km}$ al este del límite topográfico de la cordillera andina, entre el estero Reloncaví por el sur y el volcán Villarrica por el norte. Weischet (1963) sugiere que estos procesos se emplazan sobre un lineamiento estructural $\mathrm{N} 13^{\circ} \mathrm{E}$. Dos megadeslizamientos han sido citados por la literatura científica: el más conocido, conformado por cuatro deslizamientos contiguos, colapsó la desembocadura del lago Riñihue en el valle del río San Pedro, con un perímetro de corona de $500 \mathrm{~m}$ y un alto de $80 \mathrm{~m}$; el volumen total de roca, sedimentos y suelo removido fue de aproximadamente 5 millones de $\mathrm{m}^{3}$ (Davis \& Karzulovic, 1963). Otro sector severamente afectado fue el cerro Aniques y el valle del río Rihueco, cerca de Liquiñe, donde Donoso (2011) "cuenta" en sus escritos la ocurrencia de unos 60 derrumbes y del gran derrumbe del Tranguil, que desplomó la ladera de un cerro. Los depósitos cubrieron unos $2 \mathrm{~km}$ de valle y dejaron 90 personas fallecidas.

El litoral de Concepción está ubicado en la zona de subducción entre la placa oceánica de Nazca y la continental Sudamericana; región sísmicamente activa, que ha registrado el mayor número de terremotos del país, en 
periodo histórico. Seis son los eventos sísmicos con carácter de terremoto de subducción y acompañados de tsunamis destructivos, que han afectado a este sector: 28-10-1562 (M desconocida); 08-02-1570 (M: 8.5); 1503-1657 (M: 8.0); 23-05-1751 (M: 8.5); 20-02-1835 (M: 8.25); 27-02-2010 (M: 8.8) (Lomnitz, 2004; U.S.G.S., 2010). No existen estudios sistemáticos sobre los PRM detonados por estos terremotos, probablemente debido a que sus efectos son más localizados y significativamente menores a aquellos generados por el terremoto y tsunami. Por otra parte, Antinao \& Gosse (2008) han verificado que 378 grandes deslizamientos registrados durante el Cuaternario en la cordillera andina de Chile central, entre los $32^{\circ}$ y $34.5^{\circ} \mathrm{S}$ de latitud, han sido detonados por sismos superficiales intraplaca $(<20 \mathrm{~km}$ de profundidad), en tanto que grandes sismos de subducción como aquellos ocurridos en 1906 en Valparaíso (Ms 8.4), en 1943 en Illapel (Ms 7.9) o en 1985 en Santiago (Ms 8.4) han creado solo pequeños deslizamientos. Luego, frente al último terremoto de subducción acaecido el 27F de 2010 (M: 8.8 y profundidad de $30 \mathrm{~km}$ ) surgen las siguientes preguntas: ¿Cuál es la densidad y distribución de los PRM inducidos por este sismo? ¿Qué tipos de PRM se produjeron y cuáles fueron los factores condicionantes?
Bray \& Frost (2010a) han reconocido, visualmente, una gran densidad de PRM de tamaño pequeño a mediano y de carácter superficial, en laderas de quebradas, en el borde de terrazas marinas y en cortes de caminos y cerros, originados por las fuertes vibraciones sísmicas asociadas al terremoto del 27F 2010, en la Región del Biobío. ¿Estos hallazgos estarían confirmando la hipótesis de Antinao \& Gosse (2008)? La finalidad de este estudio es analizar y explicar la distribución de los PRM cosísmicos más visibles, producidos por el megaterremoto del $27 \mathrm{~F}$, en el litoral de Concepción.

\section{Métodos}

Para el logro de este objetivo se ubicaron los principales PRM; algunos de estos fueron primeramente reconocidos y georreferenciados en Google Earth (Data SIO, NOAA, US. Navy NGA GEBCO, 2012). Una vez situados, se evaluaron directamente en terreno las características morfométricas (Figura $N^{\circ} 1$ ) y los factores condicionantes (pendientes, litología, manejo de laderas, uso del suelo, etc.). Se utilizó GPS Garmin eTrex30, lupa, huincha métrica, brújula y bibliografía especializada. Entrevistas a vecinos del lugar, aportaron interesante información particularmente sobre las

Figura $\mathrm{N}^{\circ} 1$

Ejemplo de levantamiento morfométrico: desprendimiento caleta Los Bagres.

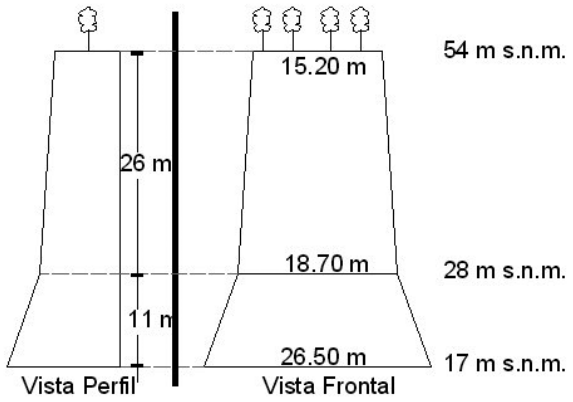

A

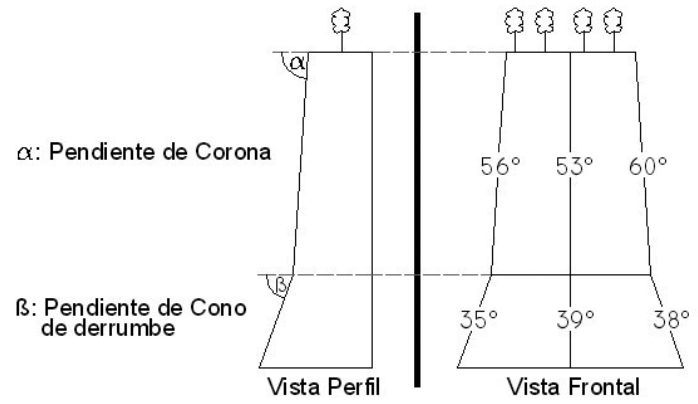

B 
Cuadro $\mathrm{N}^{\circ} 1$

Características de procesos de remoción en masa cosísmicos

\begin{tabular}{|c|c|c|c|c|c|c|}
\hline Nombre & $\begin{array}{c}\text { Tipo de } \\
\text { movimiento }\end{array}$ & $\begin{array}{c}\text { Desorganización } \\
\text { interna }\left({ }^{*}\right)\end{array}$ & $\begin{array}{c}\text { Contenido } \\
\text { de agua } \\
(* *)\end{array}$ & $\begin{array}{l}\text { Velocidad } \\
\qquad(* * *)\end{array}$ & $\begin{array}{l}\text { Profundidad } \\
\qquad(* * *)\end{array}$ & $\begin{array}{l}\text { Tipos } \\
\text { PRM }\end{array}$ \\
\hline $\begin{array}{l}\text { Desprendimiento } \\
\text { de roca y/o suelo }\end{array}$ & $\begin{array}{l}\text { Desplome en } \\
\text { masa, caída libre }\end{array}$ & $A-M A$ & Se-Hnsa & ER & $\mathrm{Su}$ & DER \\
\hline $\begin{array}{l}\text { Deslizamiento de } \\
\text { roca }\end{array}$ & $\begin{array}{l}\text { Deslizamiento } \\
\text { traslacional } \\
\text { sobre superficie } \\
\text { de corte basal }\end{array}$ & A & Hnsa-Psa & MR & $\mathrm{Su}$ & DR \\
\hline $\begin{array}{l}\text { Desprendimiento } \\
\text { de arena y suelo }\end{array}$ & $\begin{array}{l}\text { Desplome de } \\
\text { arena fluvial no } \\
\text { consolidada }\end{array}$ & M & Se & MR & $\mathrm{Su}$ & DS \\
\hline $\begin{array}{l}\text { Extensión lateral de } \\
\text { suelos }\end{array}$ & $\begin{array}{l}\text { Traslación sobre } \\
\text { zona basal de } \\
\text { arena, grava o } \\
\text { limo liquefaccio- } \\
\text { nada }\end{array}$ & M & Psa-Sa & MR & $\mathrm{Su}$ & EL \\
\hline $\begin{array}{l}\text { Remoción en masa } \\
\text { mixto }\end{array}$ & $\begin{array}{l}\text { Desplome y } \\
\text { deslizamiento }\end{array}$ & A-MA & Psa & MR-ER & Su & PRMi \\
\hline
\end{tabular}

$\left.{ }^{*}\right)$ Desorganización Interna: L: leve (deslizamiento de uno o pocos bloques coherentes); M: moderada (varios bloques coherentes); A: alta (numerosos pequeños bloques, granos de suelo individual y fragmentos de roca); MA: muy alta (desagregación completa en granos de suelo individual o fragmentos pequeños).

${ }^{(* *)}$ Contenido de agua: Se: seco; Hnsa: húmedo no saturado; Psa: parcialmente saturado; Sa: saturado. $\left.{ }^{(* * *}\right)$ Velocidad: (EL) Extremadamente lento: < 0.6m/año; (ML) muy lento: 0.6-1.5m/año; (LE) lento: 1.5m/a-1.5m/ mes; $(M O)$ moderado: $1.5 \mathrm{~m} / \mathrm{mes}-1.5 \mathrm{~m} /$ día; $(R A)$ rápido: $1.5 \mathrm{~m} /$ día- $0.3 \mathrm{~m} / \mathrm{minuto}$; $(M R)$ muy rápido: $0.3 \mathrm{~m} / \mathrm{minu}$ to-3m/segundo; (ER) extremadamente rápido: $<3 \mathrm{~m} /$ segundo.

$(* * * *)$ Profundidad: superficial: Su $(<3 \mathrm{~m})$; Pro: profundo $(>3 \mathrm{~m})$. Tipos de PRM: DER: desprendimiento de roca y suelo; DR: deslizamiento de roca; DS: desprendimiento de arena y suelo; EL: extensión lateral de suelos; PRMi: proceso de remoción en masa mixto.

Fuente: Elaboración propia a partir de Keefer (1984).

condicionantes presísmicas (ej. intervención de laderas, fecha de construcción de ruta, PRM previos). Se analizó la vulnerabilidad de la construcción mediante observación directa y a través de datos aportados por algunas municipalidades y por los residentes. Los tipos de remociones cosísmicas fueron agrupadas de acuerdo al tipo de material y tipo de movimiento, empleando los criterios de clasificación de Keefer (1984), que aparecen en el Cuadro $\mathrm{N}^{\circ} 1$.

\section{Localización y características del área de estudio}

El área de estudio se sitúa en la zona costera entre $36^{\circ} 36^{\prime}$ y $36^{\circ} 24^{\prime}$ de latitud Sur
(Figura $\mathrm{N}^{\circ} 2$ ), en el margen occidental de la cordillera de la Costa de la Región del Biobío, Chile. Desde el punto de vista geomorfológico, las unidades mayores del relieve han sido estructuradas por la tectónica de falla, que ha originado una estructura de bloques (penínsulas, islas), fosas (Ilanuras) y escarpes de falla, en rocas graníticas y metamórficas de edad Paleozoica y en rocas sedimentarias de edad terciaria. Una secuencia de bahías y penínsulas modeladas por plataformas y terrazas de abrasión marina se disponen de $\mathrm{N}$ a $S$, enmarcadas al oeste por acantilados marinos y por pequeñas y esporádicas Ilanuras litorales.

Al norte del área, se destaca la pequeña península de Tomé-Coliumo y al sur la 
gran península de Arauco. La población se concentra en el núcleo urbano ConcepciónTalcahuano, el que se emplaza en una llanura arenosa enmarcada por escarpes de falla que limitan la cordillera de la Costa constituida por roca granítica Paleozoica al E, y las penínsulas de Tumbes y Hualpén al W, labradas en rocas metamórficas, también de edad Paleozoica. Al interior de esta llanura emergen cerros isla conformados por rocas sedimentarias (lutitas, areniscas, conglomerados, etc.) de edad cretásica a terciaria; ellos son los cerros La Pólvora, Chacabuco, Chepe, San Miguel, Cosmito y la $U$, cuyos estratos rocosos se encuentran fallados y basculados. Las laderas presentan pendientes abruptas (generalmente $>20^{\circ}$ ) y las rocas muestran espesos mantos de alteración, debido a la humedad del clima (IGM, 2001).
La Ilanura está formada por arenas basálticas aportadas por el volcán Antuco, a través de los ríos Laja - Biobío. El depósito de estos sedimentos se ha realizado en un ambiente deltaico. Resultado de estos procesos es la formación de pequeños lagos y paleocanales del río Biobío, abandonados en dirección de las bahías de Concepción y San Vicente; cuyos estuarios de Rocuant y Lenga, respectivamente, fueron obstruidos y transformados en pantanos litorales, por la construcción de flechas litorales y dunas. Estos sectores bajos (humedales) han sido artificialmente rellenados. Sobre estas difíciles condiciones de sitio se han expandido las ciudades de Concepción y Talcahuano, que concentran cerca del $23 \%$ de la población regional, con densidades que superan los $1.500 \mathrm{hab} / \mathrm{km}^{2}$ en algunos distritos (INE, 2002). A partir de

Figura $\mathrm{N}^{\circ} 2$

Localización del área de estudio
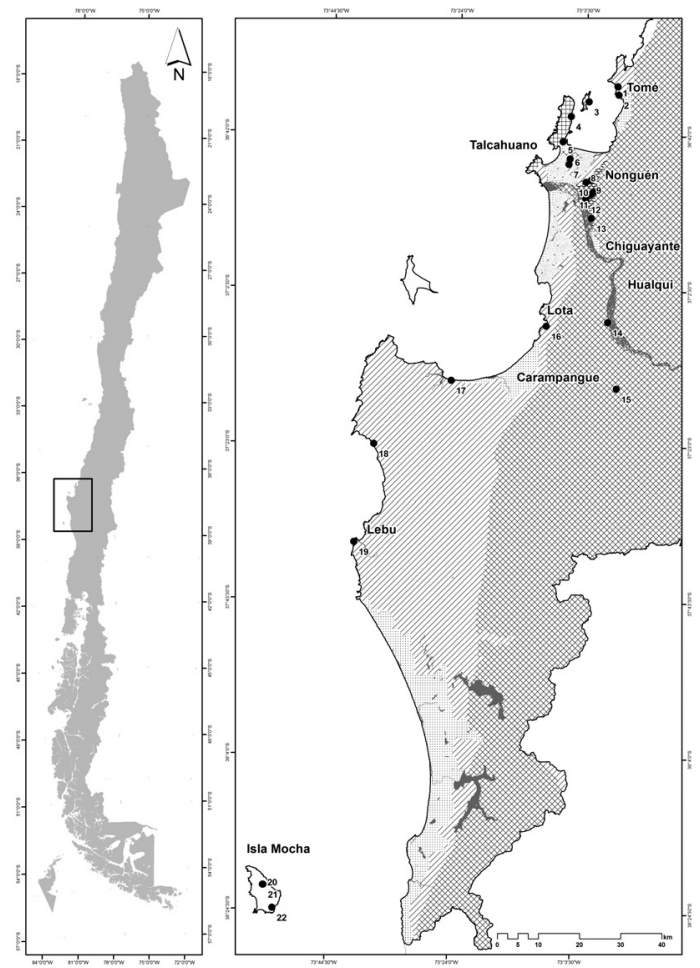

1 a 22: localización de PRM evaluados en Cuadro $N^{\circ}$ 2. Unidades geomorfológicas: cordillera de la Costa (cuadriculado oblicuo), horst de Tumbes y Hualpén (cuadriculado recto), terrazas y plataformas de abrasión marina en roca sedimentaria terciaria (achurado oblicuo); llanuras fluviales y marinas (punteado).

Fuente: Elaboración propia. 
Figura $\mathrm{N}^{\circ} 3$

Relación distancia del epicentro (SSN) de cada PRM, según perímetro de corona

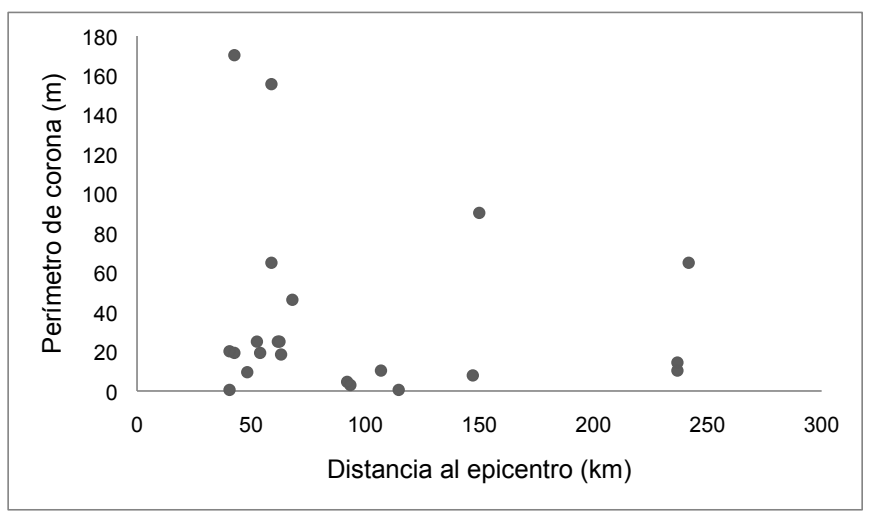

Fuente: Elaboración propia.

la segunda mitad del siglo XX, la expansión urbana ocupa las unidades físicas marginales, particularmente: laderas de cerros con pendientes en equilibrio precario y humedales. En el plano social, la ocupación del espacio se estructura en un patrón de segregación, que sigue estrictamente los dictámenes del sitio; es decir, los estratos de más bajos ingresos ocupan los sitios más desfavorables (IGM, 2001). La conectividad entre los distintos núcleos urbanos de la intercomuna y de la región, se efectúa a través de caminos que cortan laderas de cerros, a menudo sin estabilizar.

\section{Distribución y densidad de los PRM inducidos por el terremoto del $27 \mathrm{~F}$}

El hipocentro del terremoto de magnitud 8.8 $\mathrm{M}_{\mathrm{w}}$ del $27 \mathrm{~F}$ del 2010, se localizó en el mar a $36,29^{\circ}$ de latitud Sur y $73,23^{\circ}$ de longitud Oeste, a una profundidad aproximada de $30 \mathrm{~km}$ (SSN) y a una distancia de $105 \mathrm{~km}$ de Concepción. El evento sísmico generó variados tipos de PRM entre los que destacan desprendimientos de roca y de suelo (derrumbes), extensión de suelos (lateral spreading) por falta de confinamiento lateral y deslizamientos mixtos; se estudiaron las remociones en masa de mayor superficie y accesibilidad. El Cuadro $N^{\circ} 2$ sistematiza la localización y características de 22 sitios estudiados y la tipología de los PRM identificados en cada uno de estos sitios. La Figura $N^{\circ} 2$ muestra la distribución de estos lugares en la costa de la Región del Biobío.

Nuestros resultados sugieren una relación lineal entre densidad y distancia al epicentro (Figura $\mathrm{N}^{\circ} 3$ ); aunque se han visualizado PRM hasta $250 \mathrm{~km}$ al sur de este, el 68,2\% de los eventos se concentra a menos de $100 \mathrm{~km}$ del epicentro. El tamaño medio de las remociones medido por el perímetro de la corona, es de aproximadamente $20 \mathrm{~m}$ para el $50 \%$ de los eventos y se distribuyen aleatoriamente a cualquier distancia; pero los de mayor tamaño se localizan más próximos al epicentro. Patrones similares de distribución regional de PRM cosísmicos, han observado Meunier et al. (2007), asociados a los terremotos de Northridge (California), Chi-Chi (Taiwan) y Papúa (Nueva Guinea), donde el $80 \%$ de los deslizamientos se generaron en un radio de $50 \mathrm{~km}$ desde el epicentro; lo que reflejaría una atenuación de la onda sísmica con el alejamiento de este, considerando que se requiere un mínimo de agitación del suelo para que ocurra el fallo de ladera.

De los eventos observados en Concepción, un $31,8 \%$ de los procesos se localizan en áreas urbanas, la misma proporción en acantilados marinos y en cortes de camino $y$ un $4,5 \%$ en las riberas de sistemas lacustres. 
Cuadro $\mathrm{N}^{\circ} 2$

PRM cosísmicos detonados por el terremoto del 27F de 2010, evaluados en el litoral de la Región del Biobío

\begin{tabular}{|c|c|c|c|c|c|c|c|c|c|c|c|c|c|c|c|}
\hline $\begin{array}{l}\text { Loca- } \\
\text { lidad }\end{array}$ & LocalizaciónWGS84 18H & $\begin{array}{c}\text { Altitud } \\
\text { en } m \\
\text { base }\end{array}$ & L.P & $\mathrm{P}^{\circ}$ & Pem & $\mathrm{Hm}$ & $\mathrm{HcO}$ & $\mathrm{Li}$ & $\mathrm{CoH}$ & $\mathrm{CoT}$ & AlcR & $\mathrm{Vm}^{3}$ & $\mathrm{E}$ & $\mathrm{Vu}$ & TPRM \\
\hline 1 & $5948440 \mathrm{~N} / 0681346 \mathrm{E}$ & 25 & 21 & 80 & 20 & 65 & 15 & $\mathrm{a} / \mathrm{l}$ & $\mathrm{h}$ & $\mathrm{f} / \mathrm{m}$ & 10 & 3200 & $\mathrm{~V}$ & A & DR \\
\hline 2 & $5946355 \mathrm{~N} / 0681601 \mathrm{E}$ & 17 & 58 & 56 & 19 & 54 & 26 & $\mathrm{a} / \mathrm{l}$ & $\mathrm{h}$ & $\mathrm{f} / \mathrm{m}$ & 6 & $\mathrm{~s} / \mathrm{d}$ & 37 & A & DER \\
\hline 3 & $5944734 \mathrm{~N} / 0674357 \mathrm{E}$ & 0 & 48 & 37 & $s / d$ & 36 & $\mathrm{~s} / \mathrm{d}$ & $\mathrm{a} / \mathrm{l}$ & $\mathrm{s}$ & $\mathrm{f} / \mathrm{m}$ & 0 & $S / d$ & $\mathrm{c} / \mathrm{m}$ & B & DER \\
\hline 4 & $5941159 \mathrm{~N} / 0669992 \mathrm{E}$ & 0 & 100 & 42 & 170 & 90 & $s / d$ & f.m. & $s / d$ & $\mathrm{f}$ & 0 & $s / d$ & $\mathrm{c} / \mathrm{m}$ & B & PRMi \\
\hline 5 & $5935028 \mathrm{~N} / 0668007 \mathrm{E}$ & 29 & 11 & 55 & 9 & 34 & 7 & f.m & $\mathrm{h}$ & $s / d$ & 2 & $s / d$ & $\mathrm{~V} / 5$ & A & DER \\
\hline 6 & $5930842 \mathrm{~N} / 0669725 \mathrm{E}$ & 15 & 23 & 31 & 25 & 15 & 3,2 & $a / c$ & $\mathrm{~s}$ & $\mathrm{~m}$ & 32 & $\mathrm{~s} / \mathrm{d}$ & $\mathrm{V}$ & A & DER \\
\hline 7 & $5929508 \mathrm{~N} / 0669428 \mathrm{E}$ & 29 & 5,5 & 28 & 19 & 29 & 1,8 & a.m & $\mathrm{h}$ & $\mathrm{f}$ & 2 & 27,46 & 20 & A & PRMi \\
\hline 8 & $5925153 \mathrm{~N} / 0673557 \mathrm{E}$ & 30 & 63 & 55 & 65 & 65 & 35 & $\mathrm{a} / \mathrm{g}$ & $\mathrm{s}$ & $\mathrm{f} / \mathrm{m}$ & 6 & 3163 & $s / h$ & B & DER \\
\hline 9 & $5925660 \mathrm{~N} / 0674900 \mathrm{E}$ & 8 & 13 & 90 & 155 & 8 & 1,10 & r.a & $\mathrm{h}$ & $\mathrm{f}$ & 13 & $s / d$ & $\mathrm{P} / 6$ & A & EL \\
\hline 10 & $5922690 \mathrm{~N} / 0675270 \mathrm{E}$ & 16 & 12 & 47 & 25 & 26 & 8 & g.m & $\mathrm{h}$ & $\mathrm{f}$ & 5 & $\mathrm{~s} / \mathrm{d}$ & $\mathrm{H}$ & B & DER \\
\hline 11 & $5922105 \mathrm{~N} / 0674651 \mathrm{E}$ & 40 & 30 & 61 & 25 & 40 & $>11$ & g.m & $\mathrm{s}$ & $\mathrm{f}$ & 3 & $\mathrm{~s} / \mathrm{d}$ & 35 & B & DER \\
\hline 12 & $5920964 \mathrm{~N} / 0673541 \mathrm{E}$ & 12 & 28 & 63 & 18 & 28 & 8 & g.m & $\mathrm{s}$ & $s / d$ & 6 & 144 & 7 & A & DER \\
\hline 13 & $5916324 \mathrm{~N} / 674888 \mathrm{E}$ & 24 & 56 & 63 & 46 & 68 & 44 & g.m & $\mathrm{s}$ & $s / d$ & 10 & $\mathrm{~s} / \mathrm{d}$ & $\mathrm{V}$ & A & DER \\
\hline 14 & $5890908 \mathrm{~N} / 0678805 \mathrm{E}$ & 45 & 8 & 85 & 3 & 8 & 2 & a.f & $\mathrm{s}$ & n.d & 2 & $\mathrm{~s} / \mathrm{d}$ & $\mathrm{V}$ & A & DS \\
\hline 15 & $5874724 \mathrm{~N} / 0680899 \mathrm{E}$ & 120 & 18 & 45 & 8 & 15 & 6 & g.m & $\mathrm{s}$ & $s / d$ & 3 & $s / d$ & $\mathrm{~V}$ & A & DER \\
\hline 16 & $5890078 \mathrm{~N} / 0663907 \mathrm{E}$ & 36 & 7 & 80 & 4,5 & 5 & 2 & f.m & $\mathrm{s}$ & $\mathrm{f}$ & 0 & $s / d$ & $\mathrm{~V}$ & A & DER \\
\hline 17 & $5876913 \mathrm{~N} / 0640758 \mathrm{E}$ & 29 & 54 & 85 & 10 & 46 & 15 & a.m & $\mathrm{s}$ & $\mathrm{f}$ & $\mathrm{s} / \mathrm{d}$ & 10 & $\mathrm{~V}$ & A & DER \\
\hline 18 & $5867555 \mathrm{~N} / 0653506 \mathrm{E}$ & 0 & 212 & 90 & $s / d$ & 200 & 50 & $\mathrm{a} / \mathrm{l}$ & $\mathrm{s}$ & $\mathrm{f} / \mathrm{m}$ & 0 & $s / d$ & $\mathrm{c} / \mathrm{m}$ & B & DR \\
\hline 19 & $5837738 \mathrm{~N} / 0617051 \mathrm{E}$ & 0 & 160 & 35 & 90 & 113 & 75 & $\mathrm{a} / \mathrm{l}$ & $\mathrm{s}$ & $f / m$ & $\mathrm{~s} / \mathrm{d}$ & $s / d$ & $\mathrm{c} / \mathrm{m}$ & B & DR \\
\hline 20 & $5754191 \mathrm{~N} / 0594831 \mathrm{E}$ & 210 & 95 & 34 & 10 & 65 & $\mathrm{~s} / \mathrm{d}$ & $\mathrm{a} / \mathrm{l}$ & $\mathrm{h}$ & $\mathrm{f} / \mathrm{m}$ & 95 & $s / d$ & Ds & A & DER \\
\hline 21 & $5754189 \mathrm{~N} / 0594991 \mathrm{E}$ & 276 & 108 & 30 & 14 & 61 & $\mathrm{~s} / \mathrm{d}$ & $\mathrm{a} / \mathrm{l}$ & $\mathrm{h}$ & $f / m$ & 61 & $s / d$ & Ds & A & DER \\
\hline 22 & $5748594 \mathrm{~N} / 0597137 \mathrm{E}$ & 52 & 254 & 30 & 65 & 148 & $40 \mathrm{~m}$ & $\mathrm{a} / \mathrm{l}$ & $\mathrm{h}$ & $\mathrm{f} / \mathrm{m}$ & 214 & $s / d$ & Ds & A & DER \\
\hline
\end{tabular}

Localidad: 1. Caleta Cocholgüe. 2. Los Bagres; 3. Isla Quiriquina; 4. Pta. Tumbes; 5. Cerro Zaror; 6. Cerro San Martín; 7. Denavi Sur; 8. Cerro Lo Galindo; 9. Laguna Lo Galindo; 10. Cerro Lo Pequén; 11. Cerro Caracol; 12. Pedro de Valdivia; 13. Camino a Chiguayante; . 14. Camino Sta. Juana-Concepción; 15. Camino Sta. JuanaNacimiento. 16. N de Colcura. 17. W de Arauco; 18. Pta. Carneros, SW de Arauco; 19. SW de Lebu; 20. Isla Mocha, sector NE; 21. Isla Mocha, sector centro E; 22. Isla Mocha, sector SE. Características: L.P: longitud de pendiente en $\mathrm{m}$; $\mathrm{P}^{\mathrm{o}}$ : pendiente en grados; Pem: perímetro de corona en $\mathrm{m} ; \mathrm{Hm}$ : altura del escarpe remocionado en m; Hco: altura de la corona en m; Li: litología del escarpe; a.f.: arenas fluviales, basálticas; g.m granito meteorizado; a/g: areniscas sobre granito; a.m: areniscas meteorizadas; a/l: areniscas y lutitas; f.m: filitas, esquistos metorizados; a/c: areniscas y conglomerados; r.a.: relleno artificial. $\mathrm{CoH}$ : condiciones hidrológicas; s: seco; h: húmedo; CoT: condiciones tectónicas; f: falla; s/d: sin datos; m: manteo; n.d: no deformada. AlcR: alcance horizontal de la remoción; Vm3: volumen en metros cúbicos; esta es 0 cuando el material queda a mitad de ladera; E: exposición en número de personas o infraestructura, V: vía o ruta; s/h: sin habitantes; H: hospital; P: parque; c/m: cae al mar. Ds: destrucción suelo. Vu: vulnerabilidad, B: baja, A: alta; TPRM: tipo de proceso de remoción en masa según Cuadro $\mathrm{N}^{\circ} 1$.

Fuente: Elaboración propia. 


\section{Tipos de PRM cosísmicos y factores condicionantes}

\author{
Desprendimiento de roca y suelo (DER)
}

Los desprendimientos o derrumbes son procesos gravitacionales relacionados con la caída libre de fragmentos de roca o de una mezcla de roca, suelo o ambos, desde el talud hacia el pie de ladera (Keller y Blodgett, 2007). Afectan a masas rocosas y suelo seco a húmedo no saturado, los que al ser desprendidos por la sacudida sísmica descienden en caída libre, rodando o saltando a lo largo de pendientes escarpadas. Los materiales removidos se desagregan al inicio del movimiento y se mueven a altas velocidades. En la parte superior se forman superficies de ruptura abierta (corona de derrumbe) y el material desprendido se deposita al pie del talud formando un cono de bloques, vegetación y suelo, con una estructura caótica (desorganización interna muy alta).

Son los PRM más abundantes inducidos por el terremoto del $27 \mathrm{~F}$; representan el $68,18 \%$ del total de eventos reconocidos. Estos PRM se produjeron en laderas con distintas condiciones geológicas y geográficas: en rocas sedimentarias, metamórficas, ígneas, con variadas discontinuidades (diaclasas, fallas, planos de estratificación, plano de contacto roca sana/manto meteorizado), las que al ser sometidas a vibraciones sísmicas favorecieron los desprendimientos. Se distribuyen en los acantilados costeros modelados en rocas sedimentarias terciarias (sector $\mathrm{N}$ isla Quiriquina, punto 3, Figura $N^{\circ} 2$ ), en los paleoacantilados de isla Mocha (puntos 20 a 22 , Figura $\mathrm{N}^{\circ} 2$ ); en taludes de rocas metamórficas y granito paleozoico meteorizado, labrados para expansión de la ciudad (puntos $5,8,10,11$ y 12 , Figura $\mathrm{N}^{\circ} 2$ ) y en cortes de camino emplazados en todos los litotipos anteriormente citados (puntos: 6, 13, 15, 16 y 17 , Figura $N^{\circ} 2$ ). Algunos de estos procesos cortaron las rutas entre Arauco-Tubul y entre Concepción y Nacimiento. Los rangos de pendiente en que se registran los DER, fluctúa entre 31 a $85^{\circ}$ y la longitud de pendiente varía de $7 \mathrm{~m}$ en algunos cortes de camino, a $270 \mathrm{~m}$ en el paleoacantilado de Tirúa. Muchas de estas laderas mostraban condiciones de inestabilidad presísmica. Las remociones más pequeñas dejan coronas con perímetros de $4,5 \mathrm{~m}$ y las más extensas de $65 \mathrm{~m}$.

El punto 8 (Figura $N^{\circ} 2$, Cuadro $N^{\circ} 2$ ), representativo de este PRM, se localiza en la ciudad de Concepción en la ladera $\mathrm{S}$ del cerro Lo Galindo. En el lugar, dos desprendimientos ya habían sido detonados por la Iluvia, durante el invierno de 2005; con el sismo del $27 \mathrm{~F}$, los procesos se reactivaron y se agregaron otros dos. Los factores que con-

Figura $N^{\circ} 4$

Cerro Lo Galindo. Talud de origen antrópico, modelado por conos de DER

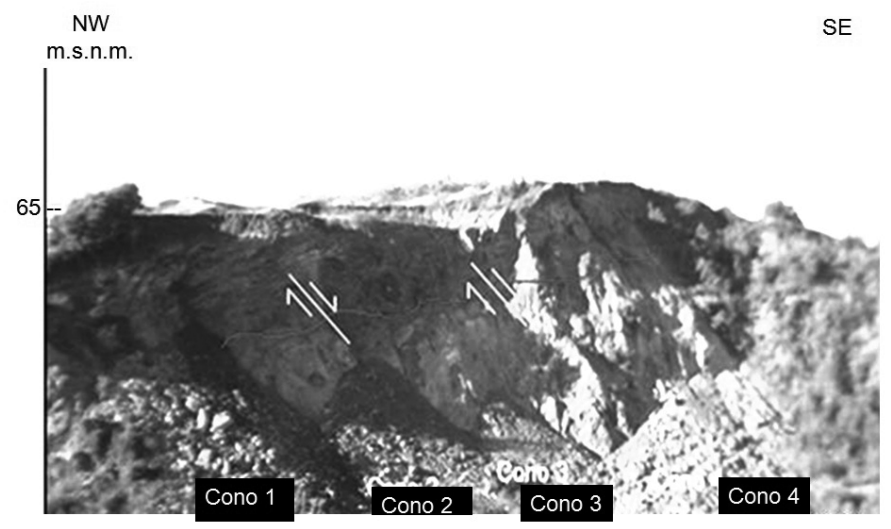

Fuente: Fotografía de C. Mora y C. Cisterna, 2010. 
tribuyeron a la ocurrencia de este desplome fueron: la pendiente crítica $>30^{\circ}$, el manteo y fallamiento de las rocas, la meteorización de la roca y la escasa cobertura vegetal. La ladera ha sido intervenida para la extracción de material, desde 1970 hasta la fecha. Esta extracción ha aumentado el vigor de la pendiente $\left(55^{\circ}\right)$ y con ello su inestabilidad. El contenido de agua en el suelo no fue significativo para el DER cosísmico. Los taludes resultantes tienen una altura media de $35 \mathrm{~m}$, la pendiente de la corona del DER es de aproximadamente $80^{\circ}$, mientras que en los conos, esta decrece hasta unos $30^{\circ}$. Los conos tienen longitudes media de $32.9 \mathrm{~m}$ y anchos promedio de $20.6 \mathrm{~m}$.

En el talud de la Figura $\mathrm{N}^{\circ} 4$ aflora la Formación Quiriquina discordantemente sobre el Batolito Costero Paleozoico. Aquella formación contiene areniscas pardas de grano fino, argilizadas, y se dispone sobre una capa de areniscas verdes con menor alteración. Ambas sobreyacen al Batolito Costero conformado localmente por monozogranito de biotita, igualmente meteorizado (Creixell, 2001). La arenisca mantea $\sim 40^{\circ} \mathrm{NW}$, anexo a lo cual se distinguen dos juegos de falla paralelas, con manteo $75^{\circ} \mathrm{E}$ y diaclasas verticales en el granito (Figura $\mathrm{N}^{\circ} 4$ ). El ancho de los conos en la sección distal alcanza a $29 \mathrm{~m}$ en el cono 1 , a $17,3 \mathrm{~m}$ en los conos 2 y 3 y a $18,8 \mathrm{~m}$ en el cono 4 .
Sobre la corona de desprendimiento, quedan grietas subparalelas, cóncavas hacia el talud, que facilitan la absorción de las aguas Iluvia y, por lo tanto, son áreas de potenciales deslizamientos.

De mayor magnitud fueron dos DER detonados por el sismo de $27 \mathrm{~F}$ en caleta Los Bagres, situada al NNW de la ciudad de Tomé (punto 2, Figura $\mathrm{N}^{\circ} 2$ ), durante el cual se desprendieron una gran cantidad de bloques de diversos tamaños. Los datos morfométricos del talud de derrumbe se presentan en el Cuadro $\mathrm{N}^{\circ} 2$. La ladera más afectada tiene $37 \mathrm{~m}$ de altura y $56^{\circ}$ de pendiente; está conformada por areniscas de la Formación Quiriquina que infrayacen a lutitas de la Formación Curanilahue, con alta densidad de diaclasas y meteorización. Sobreyace a estas un manto meteorizado de 1,5 $\mathrm{m}$ de espesor y una capa de suelo de $3 \mathrm{~m}$. Cerca de la corona surge una vertiente que hidrata la roca $y$ que pudo haber disminuido su cohesión.

El resultado morfológico fue la erosión de un talud de derrumbe de fuerte pendiente (56 a $60^{\circ}$ ), sobre el cual se visualizan una gran cantidad de grietas de tensión, que generan la permanente caída de bloques, dejando en evidencia la inestabilidad de la ladera. Esta situación se ve potenciada por la meteorización de la roca. Además, se construyó un cono de derrumbe asimétrico, variable en el

Figura $N^{\circ} 5$

Desprendimiento de roca caleta Los Bagres

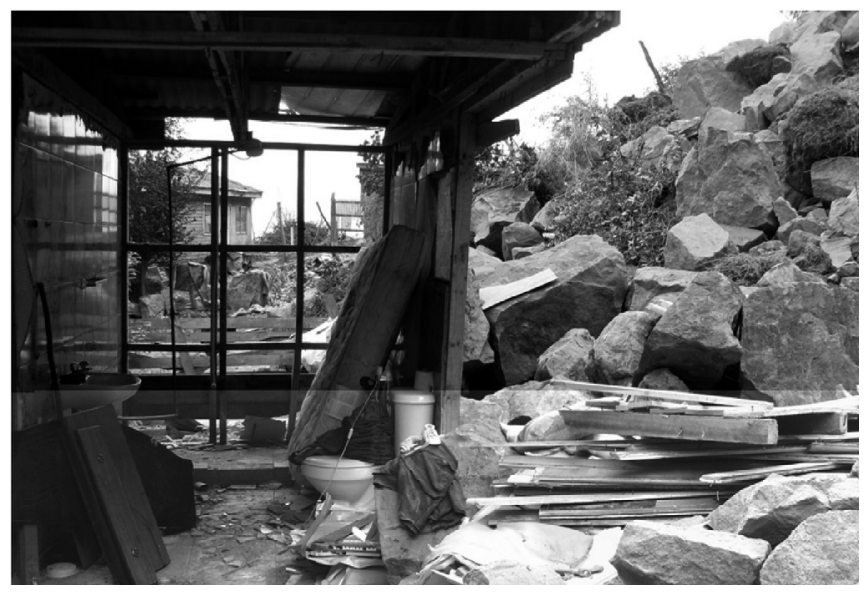

Fuente: Fotografía de K. Díaz y A. Ortega, 2010 
Figura $\mathrm{N}^{\circ} 6$

Vista panorámica del deslizamiento presísmico y su relación con la vía de acceso a caleta Cocholgüe

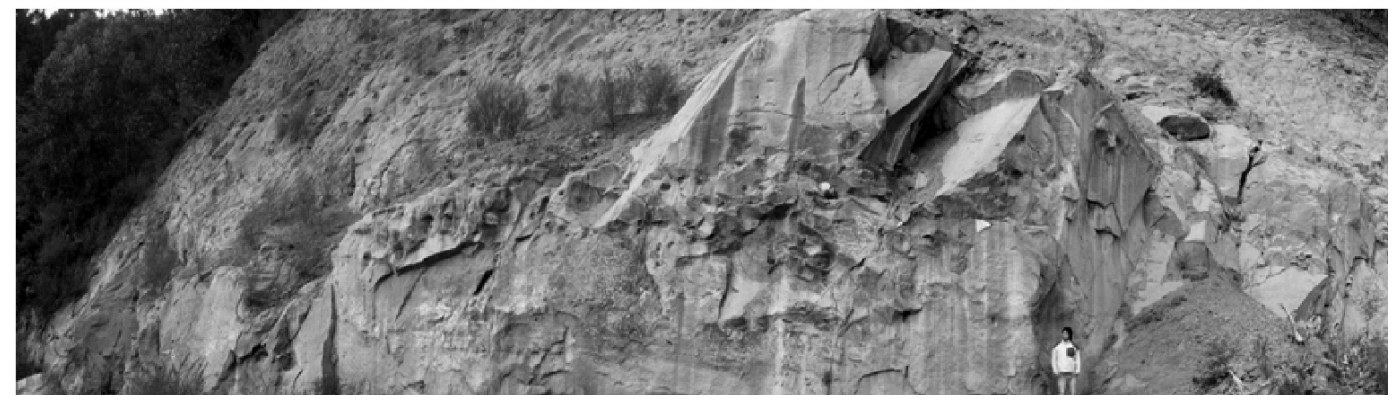

Fuente: Fotografía de L. Donoso y A. Osorio, 2009.

vigor de pendiente $\left(35\right.$ a $39^{\circ}$ ) y longitud de ladera $(20-25 \mathrm{~m})$ y conformado por bloques de diferente tamaño, aunque la mayoría de gran volumen. 37 personas fueron damnificadas por el evento, 10 casas quedaron inhabitables, 1 casa fue destruida y 1 menor resultó fallecido (Figura $N^{\circ}$ 5).

\section{Deslizamiento de rocas ( $D R)$}

Los DR son deslizamientos traslacionales de grandes masas de fragmentos de roca con una alta desorganización interna, que se mueven rápidamente sobre superficies planares con pendientes $>35^{\circ}$. Generalmente se producen en sustratos húmedos, pero no saturados (Keefer, 1984).

Se identifican tres deslizamientos de roca, superficiales, uno localizado en el margen oeste de la península de Tomé-Coliumo, sector Caleta Cocholgue, y otros dos en los acantilados marinos de la plataforma de Arauco. Estos se desarrollan sobre areniscas y limolitas del Eoceno Medio a Superior y del Mioceno, en pendientes topográficas cuyos rangos varían de 35 a más de $80^{\circ}$. No ha sido posible evaluar el volumen de material removido en los deslizamientos de la plataforma de Arauco, debido, por una parte, a la inaccesibilidad del lugar y a la remoción de gran parte del material por el tsunami asociado al terremoto.

En la ruta de acceso a caleta Cocholgüe, se han registrado varios DR. Se trata de un talud de erosión activo afectado recurren- temente por PRM detonados por las Iluvias invernales; las condiciones de este sector fueron evaluadas un año antes del terremoto, lo que favoreció el reconocimiento de los factores condicionantes del deslizamiento cosísmico (Figura $N^{\circ}$ 6). Las irregularidades topográficas en el sector sur de la caleta y la pérdida de continuidad del escarpe, dan cuenta de paleodeslizamientos y de PRM recientes; a lo que se agrega una estructura de los sedimentos en forma de paquetes en el pie del talud, producida por la presión sobre los materiales, propia de los deslizamientos rotacionales (Keller \& Blodgett, 2007). Algunos de estos procesos fueron descritos por Flores (1993). Sin embargo, la intensa intervención antropogénica en el área (construcción de taludes sin estabilizar, densificación del poblamiento costero, tala de bosques, etc.) dificulta definir con claridad la extensión y periodo de ocurrencia de dichos PRM.

Durante el sismo del 27F, este talud volvió a reactivarse, produciendo el DR cosísmico y un bloqueo total de la vía de acceso a la caleta (Figura $\mathrm{N}^{\circ} 7$ ). En el escarpe afloran rocas sedimentarias del Eoceno Medio a Superior y se ha reconocido la siguiente secuencia litológica: en la base una capa de lutitas de 2.5 $\mathrm{m}$ de espesor, alteradas y poco consolidadas; sobre estas se disponen secuencialmente una capa de areniscas cuarcíferas de grano medio a fino, poco consolidadas, de un espesor aproximado de $17 \mathrm{~m}$; un estrato de areniscas grises, fosilíferas, de grano medio, con $33 \mathrm{~m}$ de espesor; un estrato de areniscas poco consolidadas, de un espesor aproximado de $15 \mathrm{~m}$ 
Figura $\mathrm{N}^{\circ} 7$

Deslizamiento de rocas cosísmico, camino de acceso a Cocholgüe

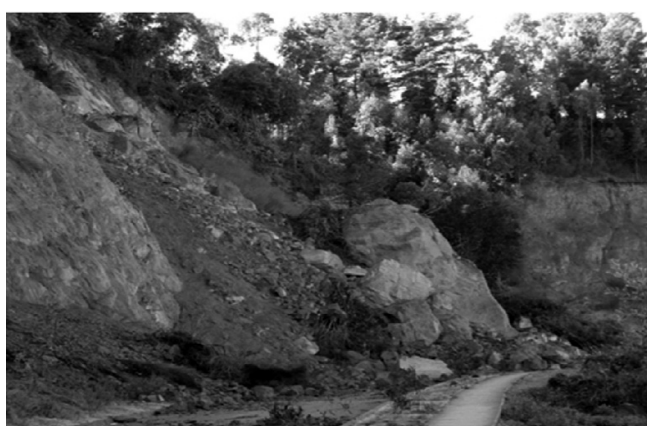

Fuente: Fotografía de H.E. Carrasco, 2010.

y en superficie una capa de suelo de unos 2 $\mathrm{m}$, con abundante vegetación y raíces. Las rocas presentan estructura fallada y un manteo de $\mathrm{N} 13^{\circ} \mathrm{O}$. Tanto la meteorización de la roca, como la estructura fallada y estratificada de estas, facilitan el desplazamiento de los materiales (Figura $\mathrm{N}^{\circ} 8$ ).

La altura promedio del talud es de $65 \mathrm{~m}$, la pendiente es de aproximadamente $80^{\circ}$ y tiene origen antrópico, ya que corresponde al corte del camino alternativo de acceso a la caleta. De acuerdo a mediciones efectuadas en laderas no intervenidas, la pendiente original era $>45^{\circ}$. El talud de deslizamiento tiene $15 \mathrm{~m}$ de alto y $20 \mathrm{~m}$ de ancho. Los clastos removidos presentan tamaños variados, aunque existen grandes bloques que no han sido disgregados. El espesor del material desprendido es de $6 \mathrm{~m}$. En vista lateral su forma es similar a un cono.

Desprendimiento de arenas y suelo (DS)

Se generaron por el desplome de sedimentos fluviales no consolidados, secos o parcialmente saturados, particularmente en cortes de camino y escarpes de terrazas fluviales. El evento analizado se produjo en un talud casi vertical (punto 14, Figura $\mathrm{N}^{\circ} 2$ ), con un largo de pendiente de $8 \mathrm{~m}$. Se formó una corona de desprendimiento de $3 \mathrm{~m}$ de ancho y $2 \mathrm{~m}$ de alto. El desplome afectó superficialmente el escarpe y el material disgregado tuvo un alcance de aproximadamente $2 \mathrm{~m}$ hacia el camino. Sus efectos fueron menores.

\section{Proceso de remoción en masa mixto (PRMi)}

Algunos movimientos en masa son combinaciones complejas de deslizamiento y flujo; son PRM de movimiento muy rápido a extremadamente rápido, que se producen en suelos parcialmente saturados. Se inician como un desprendimiento, incorporan agua cuando descienden por la ladera y se transforman en un flujo de barro al llegar al pie de esta. Este tipo de proceso se observó en una rinconada con exposición SSE del cerro Denavi Sur, donde aflora parte de la Formación Quiriquina (Cretásico superior), meteorizada, conformada por areniscas media a fina, arcilla inconsolidada y una capa de suelo limo-arcilloso (punto 7, Figura $N^{\circ} 2$ ). El sismo del $27 \mathrm{~F}$ reactivó aquí remociones anteriores a espaldas de un conjunto habitacional, cuyas casas están a menos de 0,5 m del borde del

Figura $\mathrm{N}^{\circ} 8$

Talud deslizado de caleta Cocholgüe: estructura estatificada y fallada de las rocas sedimentarias

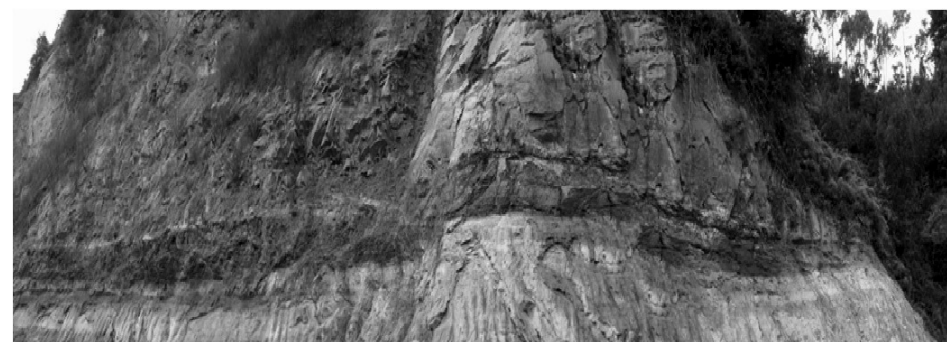

Fuente: Fotografía de L. Donoso y A. Osorio, 2009. 
talud. Los factores que han facilitado la remoción son: la meteorización de la roca que produce material inconsolidado, la saturación del manto meteorizado que opone débil resistencia al colapso y actúa como plano de deslizamiento, el ángulo de ladera $\left(28^{\circ}\right)$ y el manejo o erosión del escarpe para construir el conjunto residencial.

Se levantaron las características morfométricas de tres secciones del talud, las que son representadas en el Cuadro $N^{\circ} 3$. Se deduce, por la saturación puntual del suelo, que el agua fue incorporada desde la napa freática. La corona de desprendimiento tiene forma de arco con un perímetro total de $19 \mathrm{~m}$; presenta grietas extensionales de aproximadamente $12 \mathrm{~cm}$, por donde el agua de lluvia puede penetrar y saturar el suelo. La cima está forestada con eucaliptos adultos que implican una sobrecarga a la ladera. Este proceso depositó un volumen estimado de $27,46 \mathrm{~m}^{3}$ de barro y rocas, afectó a 20 personas e implicó la destrucción de dos viviendas. La presencia de grietas y la sobrecarga de la masa vegetal, mantienen la amenaza de deslizamientos y/o de flujos de barro en futuros años pluviosos.

El otro lugar erosionado por este tipo de PRM fue punta Tumbes (punto 4, Figura $N^{\circ}$ 2 ), donde se presentó uno de los más extensos PRMi en el borde del acantilado marino estructurado en roca metamórfica Paleozoica, meteorizada. La complejidad aquí estuvo relacionada con la perturbación previa del lugar, provocada por la explotación de una cantera para áridos. El tsunami asociado al terremoto del 27F, arrasó los depósitos acumulados en el pie del acantilado.

\section{Extensión lateral de suelos (lateral spreading) ( $E L$ )}

La EL consiste en un movimiento lateral traslacional de terrenos de suave pendiente $(0,3-5 \%)$, sobre una zona basal de sedimentos y suelos de composición limosa, arenolimosa y arena suelta de grano fino, licuefaccionada, debido a la posición relativamente superficial del techo de la napa freática. En la corona de los taludes se forman grietas, por la baja resistencia del suelo a los esfuerzos de tensión asociados a la onda sísmica. La falta de confinamiento lateral al borde de un talud, incluso con desnivel métrico, puede inducir esfuerzos de tensión en el suelo y posterior deslizamiento hacia el borde de la cara libre. Si el suelo está saturado de agua, pierde aún más fácilmente su capacidad de soporte (Rauch, 1997; Rauch \& Martin, 2000). Las unidades morfológicas más comúnmente afectadas son principalmente: Ilanuras con rellenos granulares de origen antrópico, Ilanuras deltaicas y terrazas fluviales, escarpes de riberas fluviales y lacustres y bordes de humedales, todas con pendientes topográficas mínimas de $0,3^{\circ}$ (Youd, 1977). Si bien estos procesos no amenazan la vida, pueden causar pérdidas importantes a la propiedad y deterioro ambiental (Keefer, 1984).

Cuadro $\mathrm{N}^{\circ} 3$

Parámetros morfométricos de 3 secciones medidas en PRMi cosísmico, cerro Denavi Sur, comuna de Talcahuano

\begin{tabular}{|c|c|c|c|c|c|c|c|}
\hline Sección & Dirección & $\begin{array}{c}\text { Largo de } \\
\text { la pen- } \\
\text { diente }(\mathrm{m})\end{array}$ & $\begin{array}{c}\text { Alto } \\
\text { de la } \\
\text { corona } \\
(\mathrm{m})\end{array}$ & $\begin{array}{c}\text { Ángulo de la } \\
\text { pendiente }(\mathrm{sexa}- \\
\text { gesimal })\end{array}$ & $\begin{array}{c}\text { Área } \\
\text { transversal } \\
\left(\mathrm{m}^{2}\right)\end{array}$ & $\begin{array}{c}\text { Perímetro } \\
\text { asociado } \\
(\mathrm{m})\end{array}$ & $\begin{array}{c}\text { Volumen } \\
\text { del blo- } \\
\text { que } \\
\left(\mathrm{m}^{3}\right)\end{array}$ \\
\hline 1 & $\mathrm{~N} 65^{\circ} \mathrm{W}$ & 3.63 & 1.90 & $28^{\circ} 10^{\prime} 15.52^{\prime \prime}$ & 2.178 & 5.4 & 11.76 \\
2 & $\mathrm{~N} 36^{\circ} \mathrm{W}$ & 2.57 & 3.06 & $25^{\circ} 28^{\prime} 53.64^{\prime \prime}$ & 2.686 & 4.4 & 11.82 \\
3 & $\mathrm{~N} \mathrm{7} 7^{\circ} \mathrm{W}$ & 2.52 & 0.55 & $31^{\circ} 52^{\prime} 28.37^{\prime \prime}$ & 0.441 & 8.8 & 3.88 \\
Total & & & & & & & 27.46 \\
\hline
\end{tabular}

Fuente: Levantamiento realizado por A. Figueroa y A. Obregón, 2010. 
Figura $\mathrm{N}^{\circ} 9$

Extensión lateral de suelos (EL), laguna Lo Galindo, comuna de Concepción. Vista SW-NE

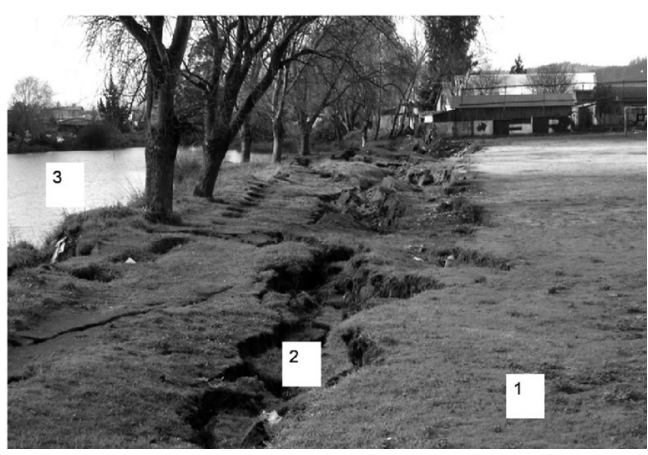

La franja desplazada está limitada por la arboleda (sobrecarga). Las grietas se ensanchan de $\mathrm{S}$ a $\mathrm{N}$, en la medida que aumenta el espesor del relleno artificial en el suelo. 1: terraza de relleno artificial de $11 \mathrm{~m}$ de ancho; 2: grietas de tensión; 3: laguna Lo Galindo.

Fuente: Fotografía de M. Mardones, junio de 2010.

En el litoral de Concepción, procesos de EL y grietas de tensión se generaron en suelos blandos, con desnivel métrico y caras libres, durante el terremoto del 27F. El paso de las ondas s sísmicas provocaron la licuación, la ruptura del suelo y finalmente el deslizamiento lateral, en los bordes de ríos (ribera norte del río Biobío, estero Maule de Coronel), lagos, lagunas (orillas de laguna Grande de San Pedro y lagunas Redonda y Lo Galindo de Concepción) y humedales (sector Los Batros), conformados por relleno artificial y suelos arenosos y arcillosos.

Laguna Lo Galindo se emplaza en la Ilanura de Concepción, en una rinconada situada en el margen oriental de los cerros de Lo Galindo, a 8 m.s.n.m. La profundidad es estimada $\leq 8 \mathrm{~m}$. La laguna tiene forma elongada, mide aproximadamente $570 \mathrm{~m}$ de longitud y $150 \mathrm{~m}$ de ancho, en su sección más amplia y $80 \mathrm{~m}$ en la más angosta. En el borde de la laguna había una terraza formada por un relleno artificial de aproximadamente $75 \mathrm{~cm}$ de espesor y $11 \mathrm{~m}$ de ancho, sobreyaciendo a arenas de dunas y limos asociados (Galli, 1967). Como consecuencia del terremoto se produjo en la ribera ENE del sistema lacustre, un deslizamiento de bloques de sedimen- tos desde la llanura, separados por grietas profundas (Figuras $\mathrm{N}^{\circ} 9$ y $\mathrm{N}^{\circ} 10$ ). El deslizamiento tiene un ancho medio de $13 \mathrm{~m}$ y 155 $\mathrm{m}$ de largo. Las grietas de desgarre tienen en promedio 1,10 m de alto. La composición y estructura del suelo deslizado se observa en la Figura $\mathrm{N}^{\circ} 11$.

El sistema lacustre se ubica sobre la línea de falla Chacabuco, de dirección SE-NW; pero no existen evidencias de que esta falla se haya activado con el sismo y tenga alguna relación con los PRM ocurridos en su borde. Todo indica que la EL se ha producido por falta de confinamiento lateral debido a la escasa compactación del suelo, al desnivel de la ribera hacia el lago $(4 \mathrm{~m})$ y a la saturación del suelo (licuación) durante el sismo. La falta de compactación es común en suelos con reIleno artificial, particularmente si el material de relleno es heterogéneo y entre esas partículas queda aire atrapado. El movimiento sísmico expulsa el aire y el agua de los poros del suelo, particularmente de aquellos sectores que tienen más sobrecarga, lo que contribuye al hundimiento de este y a la formación de grietas. El agua freática en la medida que satura los estratos inferiores del suelo, puede contribuir al deslizamiento. En la ribera de laguna Lo Galindo, el nivel del agua freática del suelo está a escaso centímetros sobre el lago. A esto se agrega que la ribera estaba ar-

Figura $\mathrm{N}^{\circ} 10$

Extensión lateral de suelos (EL), laguna Lo Galindo, comuna de Concepción.

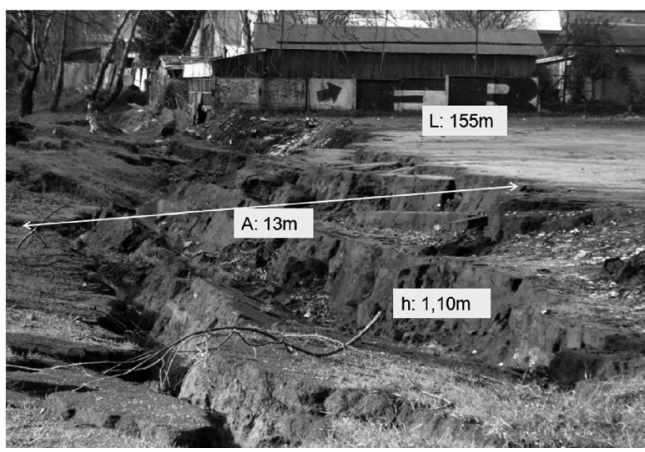

Dimensión de las grietas de tensión o desagarre. L: longitud; h: altura; A: ancho de la franja afectada por grietas.

Fuente: Fotografía de M. Mardones, junio de 2010. 
Figura $\mathrm{N}^{\circ} 11$

Composición del suelo en la sección deslizada durante el terremoto del $27 \mathrm{~F}$ en la ribera de laguna Lo Galindo.

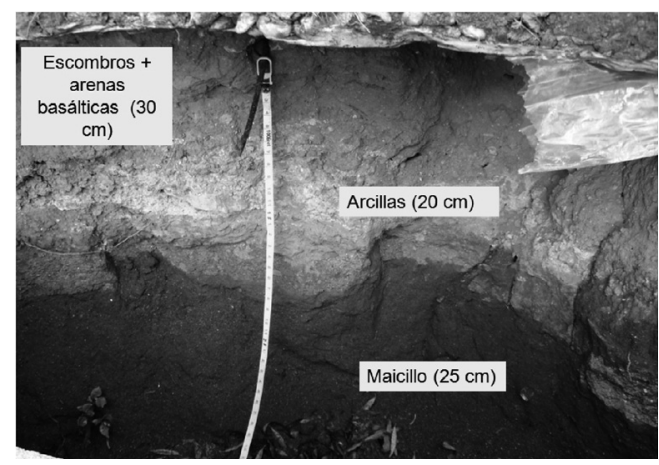

Fuente: Fotografía de M. Mardones, junio de 2010.

borizada con ejemplares robustos, cuya masa (por sobrecarga) contribuyó a activar el deslizamiento (Figura $N^{\circ} 9$ ).

Los mayores efectos de este deslizamiento fueron de tipo ecológico y social ya que perturbaron el ecosistema lacustre (la ribera se desplazó 3 m y modificó su morfología, aumentó la turbidez del lago durante el sismo), 2 casas y un pequeño paseo público fueron dañados.

\section{Consideraciones finales}

Los 22 casos de PRM cosísmicos estudiados se distribuyen en la costa de la Región del Biobío (Chile), entre las latitudes de Tomé y Tirúa; el $68,18 \%$ de ellos corresponden a algún tipo de DER, el 13,63\% a DR y menos de un $10 \%$ a PRMi. Aunque en esta investigación se evaluó un solo caso de EL, debido a que no representan tanto peligro para la población, se visualizaron abundantemente en toda el área de estudio. Los PRM fueron localizados entre 0 y 254 m.s.n.m. (altitud medida en la base del talud); las laderas arrojaron una longitud media de 65,3 m (promedio que excluye el proceso de EL) y una altura media de $57,6 \mathrm{~m}$.

El $13,6 \%$ de los eventos se ha detonado en taludes estructurados en rocas metamórfi- cas meteorizadas (principalmente acantilados marinos), el 22,7\% en áreas con afloramiento de rocas graníticas meteorizadas y el $50 \%$ en rocas sedimentarias (areniscas finas y lutitas), igualmente alteradas, con rumbo-manteo de aproximadamente $40^{\circ} \mathrm{NW}$ y juegos de falla con rumbos principalmente hacia el E. Ambos tipos de roca se presentan intensamente meteorizadas y enmantadas por un suelo de variado espesor. En más del 50\% de los casos, pese a que el proceso se produjo en verano, el suelo mostraba condiciones de humedad. La mayor parte de los procesos se produjeron en pendientes entre 46 y $80^{\circ}$ y el alcance horizontal de la masa removida fue $<$ $10 \mathrm{~m}$. En el caso de la EL, desplazamientos > $3 \mathrm{~m}$ se produjeron en el borde de ríos y lagunas por falta de confinamiento lateral.

Todos los PRM son superficiales $(<30 \mathrm{~m}$ de espesor) y de pequeña extensión (perímetros de 3 a $90 \mathrm{~m}$ de largo y volúmenes que no superan los $5.000 \mathrm{~m}^{3}$ ). Incluso aquellos cuyo volumen pudo ser exactamente evaluado tienen < de $3.200 \mathrm{~m}^{3}$. Considerando la corona de deslizamiento, se supone que los más grandes PRM fueron aquellos localizados en la costa de Lebu, en cerro Lo Galindo y en punta Tumbes, pero sus efectos no fueron significativos pues se produjeron en áreas deshabitadas. Los de mayor impacto se ubicaron en la costa de Tomé.

Nuestros resultados confirman las observaciones más globales realizadas en Chile central por Bray \& Frost (2010 a), en el sentido de que PRM detonados por el sismo del $27 \mathrm{~F}$, tuvieron escasa densidad y pequeña dimensión para la magnitud 8.8 del sismo. Aunque la distribución es un tanto aleatoria, se constata que la densidad de PRM tiene relación directa con la distancia al epicentro o zona de ruptura, consistentemente con lo señalado por Wilson \& Keefer, 1983; Keefer, 1984; Vargas, 2002. Keefer (1984) también establece una relación entre la magnitud y los tipos de remociones en masa; deslizamientos grandes y profundos, avalanchas de roca y fenómenos de EL (lateral spreading) requieren mayor agitación, sismos de gran magnitud para producirse. Aunque no se han detonado avalanchas ni grandes deslizamientos en la costa de la región, la densidad de procesos de EL relacionados con el sismo del 27F (Bray \& Frost, 2010 b) y el grado de desplazamien- 
to medido en terreno ( $>3 \mathrm{~m}$ ) en algunos de ellos, muestran la severidad del movimiento. De 71 eventos estudiados en el mundo por Rauch \& Martin (2000), solo nueve registran un desplazamiento horizontal similar al observado en este estudio; en la mayoría de los casos el deslizamiento es $<1,6 \mathrm{~m}$.

Algunos autores plantean que la intensidad sísmica estimada en roca se atenúa con la distancia al epicentro (Astroza et al., 2010); sin embargo, a partir de la experiencia del terremoto de 1985 en la zona central de Chile, Menéndez (1991) ha definido desde el punto de vista microsísmico, isosistas que permiten corregir las intensidades considerando las características locales de los suelos de fundación. Aunque no presenta resultados para roca meteorizada, sugiere que en depósitos coluviales (que podrían tener una textura semejante a dichas rocas) la intensidad sísmica podría incrementarse en 1 a 2 grados respecto de la intensidad estimada en roca y en depósitos arcillosos (de borde de ríos y lagos) hasta 2.5 grados, respecto de la intensidad estimada en roca. Es decir, en el área investigada las vibraciones producidas por el sismo del 27F, podrían haber sido notablemente superiores en la roca meteorizada y en los sedimentos húmedos que en la roca sana y seca, lo que explicaría su baja resistencia a los esfuerzos de tensión.

La estabilidad de una ladera se valora determinando la relación entre la fuerza impulsora (en este caso el sismo) y la fuerza de resistencia al corte que se opone al movimiento o factores condicionantes (Keller y Blodgett, 2007). En la zona litoral de Concepción, los PRM se concentraron donde confluía la mayor cantidad de factores condicionantes: fuerte gradiente topográfico, suelos con sobrecarga vegetacional o sin cobertura vegetal, roca muy meteorizada, diaclasada, fracturada o con múltiples planos de discontinuidad, taludes intervenidos por el hombre (erosionados, cortados para construir casas o caminos), acantilados marinos, sustratos con relleno artificial sobre suelos saturados, sedimentos incoherentes, etc. Los desprendimientos en cortes de camino dependieron fundamentalmente del grado de estabilización y de la altura del corte y de la naturaleza del material fuente: la masa desprendida fue de mayor volumen en roca meteorizada y sedimentos no compactados. Las rocas sedimentarias (areniscas y lutitas) de las formaciones Quiriquina y Curanilahue, deformadas (inclinadas y falladas) y meteorizadas, sobreyacentes a rocas plutónicas del Batolito Costero Paleozoico, igualmente alteradas, actuaron como planos potenciales de deslizamiento. El vigor y morfología de las pendientes topográficas, en todos los sitios fue producto de la intervención humana, lo que permite sugerir que un buen manejo del territorio disminuiría notablemente la ocurrencia de este tipo de procesos.

Por otra parte, nuestras observaciones muestran que aunque cerca del epicentro los PRM aumentan en densidad, el número total y extensión de los PRM no tienen relación con la magnitud del sismo del 27F, ya que incluso aquellas áreas reconocidas por la inestabilidad presísmica de sus laderas, no se reactivaron. Estos resultados serían aparentemente consistentes con lo señalado por Antinao \& Gossen (2009) y Lin et al. (2010) en el sentido que los terremotos de $>$ profundidad que $20 \mathrm{~km}$, solo producen remociones pequeñas y superficiales. Sin embargo, esta tesis se contrapone con los hallazgos de Weischet (1963) y (Schulz et al., 2012), ya que por ejemplo durante el terremoto de subducción de 1960 en Chile de M: 9.5, se registraron no solo numerosas remociones, sino dos PRM de gran magnitud; Weischet (1963) relaciona la zona de distribución de estos procesos con un lineamiento estructural (¿Falla LiquiñeOfqui?). En Japón y en la costa de Oregón, Schulz et al. (2012) han estudiado igualmente numerosos, extensos y profundos (>30m) PRM cuyos detonantes han sido los terremotos de subducción de Tohoku 2011 y de Cascadia 1700, respectivamente; ambos de M: 9. Se supone que los peaks de aceleración horizontal del suelo (2 G) son comparables, dada la semejanza en las características geológicas de estos dos lugares.

El fuerte peso de los factores condicionantes en la ocurrencia de PRM cosísmicos, fue revelado por los estudios de Denier et al. (1991) sobre el terremoto de Limón (M: 7.5; profundidad: $16,5 \mathrm{~km}$ ) ocurrido el 22 de abril de 1991 en la vertiente caribeña de Costa Rica, donde fue observada una marcada excentricidad entre las áreas más severamente 
afectadas por PRM y el epicentro del sismo. Se demostró allí una mayor implicancia del tipo de suelo, grado de saturación del suelo, vigor de la pendiente topográfica y de la carga de la masa boscosa húmeda, condiciones climáticas y geomorfológicas (índice de relieve relativo) y contexto geotectónico (proceso de ruptura múltiple), que de la cercanía del epicentro. Estos autores también demostraron que los sectores secos fueron menos dañados por los PRM y las grandes remociones se produjeron a menos de $10 \mathrm{~km}$ del epicentro.

Es probable que la baja densidad y reducido tamaño de los PRM en la costa de la Región del Biobío, en relación a la magnitud del sismo del 27F, se expliquen por las condiciones topográficas del relieve (altitudes $<300$ m) y por la baja humedad del suelo dado que el sismo ocurrió en verano (estación seca de clima mediterráneo), cuando los niveles freáticos estaban más bajos y las laderas secas.

Esperamos que nuestros resultados contribuyan a comprender los patrones de comportamiento de las laderas y escarpes de áreas costeras durante terremotos de subducción. Sin duda, se plantea la necesidad de realizar estudios más completos sobre la incidencia de los factores locales en la ocurrencia de PRM cosísmicos.

\section{Referencias bibliográficas}

ALARCÓN, F. Los riesgos naturales en el área metropolitana de Concepción a través de la información del Diario El Sur, 1960-1990. Concepción: Memoria para optar al título de Profesor de Historia y Geografía, Departamento de Historia, Universidad de Concepción, 1995.

ANTINAO J.L. \& GOSSE J. Large rockslides in the Southern Central Andes of Chile (32-34.5 ${ }^{\circ}$ ): Tectonic control and significance for Quaternary landscape evolution. Geomorphology, 2008, № 104, p. 117-133.

ASTROZA, M.; CABEZAS, F.; MORONI, M.O.; MASSONE, L.; RUIZ, S.; PARRA, E.; CORDERO, F. y MOTTADELLI, A. Intensidades sísmicas en el área de daños del terremoto del 27 de Febrero del 2010. Santiago de Chile: Departamento de Ingeniería Civil,
Facultad de Ciencias Físicas y Matemáticas, Universidad de Chile, 2010 (inédito).

BRAY, J. \& FROST, D. (Editors). section 10. Slope stability and landslides. Geo-Engineering Reconnaissance of the February 27, 2010 Maule, Chile Earthquake. Report of the National Science Foundation-Sponsored Geoengineering Extreme Events Reconnaissance (GEER), Version 2, 2010 a.

BRAY, J. \& FROST, D. (Editors). section 6. Liquefaction and lateral spreading. Geo-Engineering Reconnaissance of the February 27, 2010 Maule, Chile Earthquake. Report of the National Science Foundation-Sponsored Geoengineering Extreme Events Reconnaissance (GEER), Version 2, 2010b.

CREIXELL, C. Petrología y geotermobarometría de las rocas intrusivas de la Cordillera de la Costa entre los $36^{\circ} 30^{\prime}$ y $38^{\circ} 00^{\prime} \mathrm{S}$. Concepción: Memoria para optar a título de Geólogo. Departamento de Ciencias de la Tierra, Universidad de Concepción, 2001 (Inédito).

CRUDEN, D.M. A simple definition of a landslide. Bulletin International Association. Engineering Geology, 1991, № 43, p. 27-29.

DAVIS, S.N. \& KARZULOVIC, J. Landslides of Lago Riñihue, Chile. Geological Society of America Bulletin, 1963, Vol. 53, N 6 , p. 1403-1414.

DENIER, P.; PERSONIUS, S. y ARIAS, O. Generalidades sobre los efectos geológicos del terremoto de Limón. Revista Geológica de América Central, 1991, Vol. Especial Terremoto de Limón, p. 29-38.

DONOSO, J. El escribidor intruso: artículos, crónicas y entrevistas (fragmentos). Revista Anales, 2011, №1, p. 179-190.

ESSMAN, C. Zonificación, análisis y evaluación de los desastres naturales en el Área Metropolitana de Concepción, entre los años 1885-1920. Diario El Sur. Concepción: Memoria para optar al título de Profesor de Historia y Geografía, Departamento de Historia, Universidad de Concepción, 1997. 
FLORES, M. P. Zonificación y jerarquización de riesgos geomorfológicos en Caleta Cocholgüe, comuna de Tomé, VIII Región. Santiago de Chile: Tesis para optar al título de Geógrafo y al grado de Licenciado en Geografía, Pontificia Universidad Católica de Chile, 1993.

GALLI, C. Geología urbana y suelo de Fundación de Concepción y Talcahuano, Chile. Concepción: Informe Final del Proyecto de Investigación $\mathrm{N}^{\circ} 75$ de la Comisión Científica de Investigación de la Universidad de Concepción, 1967.

HAUSER, A. Remociones en masa en Chile. Santiago de Chile: SERNAGEOMIN, Boletín No 59, 2000.

INSTITUTO GEOGRÁFICO MILITAR (IGM). Geografía de Chile. Tomo VIII Región del Biobío. Santiago de Chile: IGM, 2001.

INSTITUTO NACIONAL DE ESTADISTICAS (INE). Censo de Población y Vivienda. Santiago de Chile: INE, 2002.

KEEFER, D. Landslides caused by earthquakes. Geological Survey of America Bulletin, 1984, Vol. 95, p. 406-421.

KEEFER, D. Investigating landslides caused by earthquakes. A historical review. Surveys in Geophysics, 2002, Vol. 23, $\mathrm{N}^{\circ}$ 6, p. 473510.

KELLER, E. y BLODGETT, R.H. Riesgos naturales. Madrid: Pearson Educación S.A., 2007.

LAFFAILLE, J.; FERRER, C. \& LAFFAILLE, C. Venezuela: the construction of vulnerability and its relation to the high seismic risk. In: LATRUBESSE, E. (Editors). Natural Hazards and Human -Exacerbated disasters in Latin America, Developments in Earth Surface Processes, 2010, Vol. 13, Chapter 5. Amsterdam: Elsevier Science, p. 99-129.

LIN, A.; REN, Z.; JIA, D. \& MIYAIRI, Y. Evidence for a Tang-Song Dynasty great earthquake along the Longmenshan Thrust Belt prior for the $2008 M_{w} 7,9$ Wenchuan earthquake, China. Journal of Seismology, 2010, $\mathrm{N}^{\circ} 14$, p. 615-628.
LOMNITZ, C. Major Earthquakes of Chile: A Historical Survey, 1535/1960. Seismological Research Letters, 2004, Vol. 75, №3, p. 368378.

MARDONES, M.; ECHEVERRÍA, F. y JARA, C. Una contribución al estudio de los desastres naturales en Chile Centro Sur: efectos ambientales de las precipitaciones del 26 de junio del 2005 en el área Metropolitana de Concepción. Revista Investigaciones Geográficas, 2006, Vol. 38, p. 1-25.

MENÉNDEZ, P. Atenuación de las intensidades del sismo del 3 de marzo de 1985 en función de la distancia a la zona de ruptura y del tipo de suelo. Santiago de Chile: Memoria para optar al título de Ingeniero Civil, Facultad de Ciencias Físicas y Matemáticas. Universidad de Chile, 1991.

MEUNIER, P.; HOVIUS, N. \& HAINES, J. Regional patterns of earthquake-triggered landslides and their relation to ground motion. Geophysical Research Letters, 2007, Vol. 34, p. L20408, doi: 10.1029/2007 GL031337.

OUIMET, W.B. Tectonic geomorphology. The hills came tumbling down. Nature Geoscience, 2011, Vol. 4, p. 424-425.

PARKER, R.N.; DENSMORE, A.; ROSSER, N.; DE MICHELE, M.; LI, Y.; HUANG, R.; WHADCOAT, S. \& PETLEY, D. Mass wasting triggered by the 2008 Wenchuan earthquake is greater than orogenic growth. Nature Geoscience, 2011, Vol. 4, p. 449-452.

RAUCH, A. An Empirical Method for predicting surfaces displacements due liquefaction-Induced lateral spreading in earthquakes. Virginia: Dissertation submitted to the Faculty of the Virginia Polytecnique Institute and State University in partial fulfillment of the requeriment for the degree of Dr of Philosophy in Civil Engineering, 1997, p. 17-43.

RAUCH, A. \& MARTIN, J. EPOLLS model for predicting average displacements on lateral spreads. Journal of Geotechnical and Geoenvironmental Engineering, 2000, p. 360-371.

SCHULZ, W.H.; GALLOWAY, S.L. \& HIGGINS, J. D. Evidence for earthquake triggering of large landslides in coastal Oregon, USA. 
Geomorphology, 2012, № 141-142, p. 8898.

US GEOLOGICAL SURVEY (U.S.G.S), 2010. Disponible en Internet:

http://earthquake.usgs.gov/earthquakes/world/ historical country.php\#chile.

VARGAS A., J.P. Deslizamientos inducidos por sismos y sus efectos en abanicos aluviales. Lima: Biblioteca del Instituto Geofísico del Perú. Compendio de trabajos de investigación CNDG, 2002, Vol. 3, p. 125-136.

VARNES, D. J. Slope movement types and processes. In: SCHUSTER, R. L. \& KRIZEK, R.J. (Editors). Transportation and Road Research Board. Washington D.C.: Special
Report 176: Landslides: Analysis and Control National Academy of Science, 1978, p. 11-33.

WEISCHET, W. Further observations of geologic and geomorphic changes resulting from catastrophic earthquake of may 1960, in Chile. Bulletin of the Seismological Society of America, 1963, Vol. 53, № 6, p.1237-1257.

WILSON, R. \& KEEFER, D. Dynamic Analysis of a slope failure from the 6 August 1979 Coyote Lake, California, earthquake. Bulletin of the Seismological Society of America, 1983, Vol. 73, № 3, p. 863-877.

YOUD, T.L. Packing changes and liquefaction susceptibility. Journal of the Geotechnical Engineering Division, 1977, № 103, p. 918 922. 